\title{
Religião romana nos livros iniciais do De re rustica varroniano*
}

\author{
Matheus Trevizam \\ FALE-UFMG \\ matheustrevizam2000@yahoo.com.br
}

\section{RÉSUMÉ}

Dans ce travail, on désirait tourner notre regard vers la présence du sacré et du religieux aux pages du De re rustica varronnien, c'est à dire, à ces questions comme formulées au premier et au deuxième livre de cet ouvrage. Puisque le lecteur de ces livres anciens se voit presque toujours en face de descriptions de la vie et des pratiques paysannes, comme menées en Italie pendant le premier siècle av. J.-C., il nous faut attendre ici des informations de Varron sur l'entrelacement entre les cotés tout simplement matériaux de la vie aux fundi rustici et la(les) spiritualité(s) payenne(s).

MOTS-CLÉS: De re rustica; Varron réatin; religiosité; théologie payenne; vie rustique.

Temos notícia, por certos testemunhos antigos e modernos, de que o erudito romano Varrão reatino (115-27 a.C.) dividira a religião, em suas agora perdidas Antiquitates diuinae, entre aquela "dos poetas" (mítica), aquela “dos filósofos" (natural) e aquela "das cidades" (civil), concedendo, como sábio estudioso de vários assuntos históricos, culturais e "científicos", compreensível primazia à segunda: é que, como nos relata Santo Agostinho ${ }^{1}$ no sexto livro de seu De ciuitate Dei, enquanto os juízos sobre os deuses que expressava a poesia pelos mitos lhe pareciam distorcer feiamente a sublimidade dos entes supremos ${ }^{2}$ e a vivência "civil"3 do sagrado, por necessária que

\footnotetext{
* Este artigo se insere como parte do projeto de pesquisa "Tradução anotada e estudo dirigido do segundo livro do De re rustica de Varrão de Reate", desenvolvido na FALE-UFMG pelo "Programa de auxílio para a pesquisa dos doutores recém-contratados", com o apoio da PRPq. Foi, originalmente, apresentado em versão resumida na "IX Semana de Eventos da Faculdade de Letras" (SEVFALE), em 19 de outubro de 2009, com o título: "Religião romana no De re rustica varroniano".

${ }^{1}$ Citado por Boissier, P. Étude sur la vie et les ouvrages de M. T. Varron. Paris: Hachette, 1861, p. 206207 (esta obra sobre Varrão, agora antiga de seus cento e quarenta e oito anos, permanece ainda respeitável pela amplitude e exaustiva documentação do biógrafo em várias fontes primárias antigas).

${ }^{2}$ Cf. De ciuitate Dei VI, 5, 1: Primum, inquit, quod dixi, in eo sunt multa contra dignitatem et naturam immortalium ficta. In hoc enim est, ut deus alius ex capite, alius ex femore sit, alius ex guttis sanguinis natus; in hoc, ut dii furati sint, ut adulterauerint, ut seruierint homini: denique in hoc omnia diis attribuuntur, quae non modo in hominem sed etiam quae in contemptissimum hominem cadere possunt. "En el primero - dice - que he citado se encuentran muchas mentiras contra la dignidad y la naturaleza de los immortales. En él se dice que un dios procede de la cabeza; otro, del musclo; otro, de gotas de sangre. También se dice que los dioses han robado, han cometido adulterios, han sido esclavos del hombre. Finalmente, se atribuyen a los dioses todos los desatinos que pueden sobrevenirle hasta al hombre más despreciable" (tradução de Santos Santamarta del Río e Miguel Fuertes Lanero).

${ }^{3}$ Cf. De ciuitate Dei VI, 5, 3: Intueamur sane et ciuilem theologiam. "Tertium genus est, inquit, quod in urbibus ciues, maxime sacerdotes, nosse atque administrare debent. In quo est, quos deos publice colere, quae sacra et sacrificia facere quemque par sit". - "Examinemos ya la teología civil: "La tercera clase es - dice - la que deben conocer y poner por obra en las ciudades sus habitantes y de modo especial los sacerdotes. En ella se contienen los dioses que debe honrar cada uno y las ceremonias y sacrificios que debe realizar" " (tradução de Santos Santamarta del Río e Miguel Fuertes Lanero).
} 
fosse à coesão do membros de um povo, não alcançava o máximo grau de rigor na depreensão da essência do divino, ao ponto de vista restante, especulativo e de todo desligado de vãos temores e preconceitos, cabia desvendar seguro as brumas desses mistérios. ${ }^{4}$

Não se deve, com isso, entender que, em sua obra, o autor sempre se tenha apegado apenas à visão "natural" (ou filosófica) do sagrado, sem incorporar as demais às linhas de seus escritos ou, ainda, reconhecer-lhes algum papel no seio da imaginação e das sociedades humanas. Dessa maneira, o mesmo Varrão para quem se devia acatar com paciente condescendência as lendas dos povos que os faziam enraizar-se em deuses e heróis fabulosos ${ }^{5}$ e que vê, sobretudo, fins politicamente úteis na religião institucionalizada dos Pontífices e dos ritos comuns, ${ }^{6}$ soube difundir, como nos recorda Boissier, ${ }^{7}$ a erudita abordagem de mitos em suas obras e, na verdade, até direcionar o modo de focalização do fenômeno religioso nas próprias Antiquitates diuinae para o âmbito "civil", 8 de acordo com a terminologia por ele mesmo utilizada. De fato, ao esclarecer os motivos de ter-se dedicado nesta obra teológica à descrição das práticas, crenças e cultos religiosos segundo ancestralmente seguidos em Roma, o autor emprega a curiosa imagem da pré-existência do pintor e do construtor ao quadro e ao edifício, por isso dando a entender que, assim como aqueles especialistas operam habilidosos e com vistas ao geral proveito de suas obras, os anônimos "codificadores" das religiões dos povos foram-nas aos poucos estabelecendo com fins de favorecimento dos nexos políticos e de poder nas cidades, bem como da instrumentalização do sagrado para as

\footnotetext{
${ }^{4}$ Cf. De ciuitate Dei VI, 5, 3: Quis non uideat, cui palmam dederit? Vtique secundae, quam supra dixit esse philosophorum. Haec enim pertinere testatur ad mundum, quo isti nihil esse excellentius opinantur in rebus. - "Quién no hecha de ver a cuál concede la palma? Ciertamente a la segunda, que dijo arriba era la de los filósofos. Pues afirma que ésta pertenece al mundo, lo más excelente, dicen éstos, que hay en las cosas" (tradução de Santos Santamarta del Río e Miguel Fuertes Lanero).

${ }^{5}$ Cf. Deschamps, L. Varron et le sacré. Bulletin de l'association Guillaume Budé. Paris, p. 290-291, juin 1990.

${ }^{6}$ Cf. Boissier, op. cit., p. 214-215.

${ }^{7}$ Cf. Boissier, op. cit., p. 210.

${ }^{8}$ Cf. De ciuitate Dei VI, 2: Cum uero Deos eosdem ita coluerit, colendosque censuerit, ut in eo ipso opere litterarum suarum dicat se timere ne pereant, non incursu hostili, sed ciuium negligentia, de qua illos uelut ruina liberari a se dicit, et in memoria bonorum per huius modi libros recondi atque seruari utiliore cura, quam Metellus de incendio sacra Vestalia, et Aeneas de Troiano excidio penates liberasse praedicantur. - "Sin embargo, en tal forma dio culto a esos mismos dioses y lo recomendó, que en esos mismos escritos suyos lamenta puedan perecer, no por un ataque hostil, sino por la negligencia de los ciudadanos. De esa ruina afirma que los libra él, guardándolos en la memoria de los buenos con esos libros y conservándolos con diligencia más eficaz de la que se pregona emplearon Metelo para librar a las vestales del incendio, y Eneas para librar a los penates de la destrucción de Troya" (tradução de Santos Santamarta del Río e Miguel Fuertes Lanero).
} 
necessidades quotidianas dos indivíduos. ${ }^{9}$ Em outras palavras, por exemplo, a existência e culto da deusa Roma, a pátria mesma divinizada, ou Fides (Boa-Fé), guardiã de um dos valores fulcrais da cultura latina ${ }^{10}$ - bem como a destacada e antiga presença de tantas magistraturas e Colégios sacerdotais na Cidade! $!^{11}$ - em alguma medida favorecia a união civil em respeitoso acato aos valores comuns.

Numa obra com as características do De re rustica, em que o autor, como se sabe, cindiu o todo da abordagem das técnicas e práticas rurais em três livros por sua afinidade temática, ${ }^{12}$ pode-se dizer que se destacam, nas duas partes aqui enfocadas, as visões "mítica" e "civil" do sagrado. Assim, como nos encontramos diante de um texto complexamente construído segundo os ditames do gênero dialógico, em que personagens de romanos coevos a Varrão interagem despretensiosamente sobre temas agrários vinculados ao cultivo no livro inicial e à pecuária no segundo, posicionando-se de forma, até, preceituadora sobre realidades concretas $^{13}$ alheias a grandes desenvolvimentos intelectuais, a filosofia cede espaço à evocação de lendas e tradições ligadas aos deuses e a certos ritos comumente dedicados a eles em datas específicas do calendário sagrado latino.

\footnotetext{
${ }^{9}$ Cf. De ciuitate Dei VI, 4, 2: Varronis igitur, confitentis ideo se prius de rebus humanis scripsisse, postea de diuinis, quia diuinae istae ab hominibus institutae sunt, haec ratio est: "Sicut prior est, inquit, pictor quam tabula picta, prior faber quam aedificium; ita priores sunt ciuitates, quam ea quae a ciuitatibus instituta sunt". - "Hasta el mismo Varrón declara que escribió primero sobre las cosas humanas y después sobre las divinas, porque las divinas fueron instituidas por los hombres: 'Como es antes el pintor - dice - que el cuadro pintado, y antes el arquitecto que el edifício, así son antes las ciudades que lo establecido por ellas' " (tradução de Santos Santamarta del Río e Miguel Fuertes Lanero). ${ }^{10}$ Cf. Pereira, M. H. R. Estudos de história da cultura clássica. II volume: cultura romana. Lisboa: Gulbenkian, 1990, p. 322: Sucede que a divindade deste nome é tão antiga entre os Romanos que chega a ser legítimo duvidar se o substantivo próprio antecedeu o comum.

${ }^{11}$ Cf., sobre a vitalidade da atuação dos Colégios religiosos romanos no tempo de Augusto, exemplo de Res gestae Diui Augusti IX: Vota pro ualetudine mea suscipi per consules et sacerdotes quinto quoque anno senatus decreuit. Ex iis uotis saepe fecerunt me uiuo ludos aliquotiens sacerdotum quattuor amplissima collegia, aliquotiens consules. Priuatim etiam et municipatim uniuersi ciues unanimiter continenter apud omnia puluinaria pro ualetudine mea supplicauerunt. - "O senado decretou que votos por minha saúde fossem feitos pelos cônsules e sacerdotes a cada quatro anos. Por esses votos, enquanto vivi, frequentemente fizeram jogos, ora quatro enormes colégios sacerdotais, ora os cônsules. Também individualmente ou coletivamente em seus municípios todos os cidadãos unânime e continuamente consagraram, diante de cada altar, votos por minha saúde" (tradução de Matheus Trevizam e Antônio Martinez de Rezende).

${ }^{12}$ Cf. Grimal, P. La littérature latine. Paris: Fayard, 1994, p. 217: Le premier livre traite de la culture des champs, le second de l'élevage, le troisième du "petit-élevage": gibiers divers, poissons, abeilles. Le tableau qui en résulte mêle les traditions nationales, qui formaient déjà le fond du "De agri cultura" de Caton, et les innovations les plus modernes: les volières, les garennes, les viviers, etc., suscitées par une économie orientée vers les marchés urbains.

${ }^{13}$ Cf. Della Corte, F. Passato e presente in Varrone. In: Opuscula VI. Genova: Istituto di Filologia Classica e Medievale, 1978, p. 103: Grande proprietario terriero, Varrone non si occupava, come Virgilio, dei piccoli campi, ma si rivolgeva ai coltivatori e allevatori che non meno dei lauti guadagni amavano il lusso sfarzoso.
} 
De início, portanto, interessa lembrar que Varrão, seguindo um procedimento construtivo de natureza literária que seria, poucos anos depois, reproduzido pelo Virgílio das Geórgicas, ${ }^{14}$ dota cada um dos livros da tríade do De re rustica de uma espécie de prólogo, no qual se introduz de leve o tom da discussão temática a seguir-se e, entre outras coisas, faz-se uma dedicatória das sucessivas partes da obra a alguém. ${ }^{15}$ O prólogo do livro primeiro do De re rustica, que também lhe serve, pela posição, de introdução geral para o todo do tríptico, opera pela entrada do religioso "civil" já nas linhas iniciais do texto: nessa passagem, assim, enumeram-se doze deuses "rústicos", no todo distintos daquele grupo canônico dos grandes numes olímpicos, mas obviamente dotados de elos com a vida rural romana e, em conjunto, passíveis do acato por um "nicho" de adoradores:

Primeiro, os que abrangem todos os frutos da agricultura com o céu e a terra, Júpiter e Tellus; e assim, já que são chamados de grandes pais, que Júpiter seja chamado de "pai" e Tellus de "mãe Terra". Em segundo lugar, o Sol e a Lua, cujas fases são observadas quando se planta ou armazena algo. Em terceiro, Ceres e Líber, já que seus frutos são extremamente necessários à sobrevivência, pois deles provêm o alimento e a bebida da propriedade. Em quarto, Robigo e Flora, por cujo benefício a ferrugem não estraga os grãos e as árvores e elas não florescem fora de época. Assim, foram oficialmente estabelecidas as comemorações da Robigalia para Robigo e os Jogos Florais para Flora. Também reverencio Minerva e Vênus: a uma cabe a guarda do olival; à outra, dos jardins; em seu nome, a Vinalia rústica foi estabelecida. Além disso, também suplico a Linfa e Bom Evento, já que, sem água, todo cultivo se desseca e perde e, sem sucesso e um bom resultado, há esperanças vãs, não o cultivo. ${ }^{16}$

Como se pode observar, as divindades, cinco masculinas e sete femininas, são dispostas sob a forma de cinco "casais" e uma dupla (no caso de Minerva e Vênus), segundo, até certo ponto, a partilha de atributos por ambos os membros de cada par. No

\footnotetext{
${ }^{14}$ Sobre as afinidades entre o De re rustica de Varrão e as Geórgicas de Virgílio, cf. verbete "Varrone" da Enciclopedia Virgiliana (Roma: Istituto della Enciclopedia italiana, 1990. Vol. V).

${ }^{15}$ De re rustica I, bem como o todo da obra, é dedicado a Fundânia, esposa de Varrão; De re rustica II, a Turrânio Níger; De re rustica III, enfim, a Pínio.

${ }^{16}$ Cf. prólogo de De re rustica I, 4-6: Primum, qui omnis fructos agri culturae caelo et terra continent, Iouem et Tellurem: itaque, quod ii parentes magni dicuntur, Iuppiter pater appellatur, Tellus terra mater. Secundo Solem et Lunam, quorum tempora obseruantur, cum quaedam seruntur et conduntur. Tertio Cererem et Liberum, quod horum fructus maxime necessari ad uictum: ab his enim cibus et potio uenit e fundo. Quarto Robigum ac Floram, quibus propitiis neque robigo frumenta atque arbores corrumpit, neque non tempestiue florent. Itaque publice Robigo feriae Robigalia, Florae ludi Floralia instituti. Item adueneror Mineruam et Venerem, quarum unius procuratio oliueti, alterius hortorum; quo nomine rustica Vinalia instituta. Nec non etiam precor Lympham ac Bonum Euentum, quoniam sine aqua omnis arida ac misera agri cultura, sine successu ac bono euentu frustratio est, non cultura (minha tradução).
} 
primeiro "casal", desse modo, vemos Júpiter, deus máximo do Panteão romano, ${ }^{17}$ a quem se associavam a direção do mundo, a luminosidade diurna e os fenômenos atmosféricos violentos (raios, trovões, tempestades...), e Tellus, a própria Terra-mãe divinizada pelos latinos em sua face de provedora e geradora da vida para todos os entes viventes. ${ }^{18}$ A dupla seguinte, Sol e Lua, sem deixar de ter associações tardias na mitologia greco-romana com Apolo e sua irmã Diana, ${ }^{19}$ surge aqui de forma menos aculturada, isto é, sem os refinamentos da antropomorfização, para, apenas, mostrá-los como forças ambiguamente situadas entre o sagrado e o natural. Vale dizer que o calendário latino, de bases eminentemente astronômicas e religiosas, desde cedo buscou levar em conta fenômenos a envolverem os dois astros citados, a exemplo das fases mensais da lua e da própria completude anual da circunvolução da Terra em torno do sol. ${ }^{20}$ Ceres e Líber, de imediato afins ao alimento sólido (o pão) ou ao líquido (o vinho), e possíveis correspondentes dos gregos Deméter e Baco, conheceram, em Roma, alguma instrumentalização oficial de seu culto: havia, pois, as Cerialia, festas celebradas pelo sacrifício de uma porca em honra da deusa a cada dezenove de abril, ${ }^{21} \mathrm{e}$ as Liberalia, associadas a Líber, a cada dezessete de março; ${ }^{22}$ Ceres também era celebrada com Tellus na data móvel das Feriae Sementiuae, em que se pedia resguardo para as sementes já plantadas nos campos. ${ }^{23}$ Robigo e Flora, entidades que se cria tradicionalmente afetarem para o mal ou o bem a saúde das plantas de cultivo (fazendoas adoecerem de "ferrugem" ou florescer), eram respectivamente celebrados a vinte e cinco de abril e a três de maio, ${ }^{24}$ também se associando a essa deusa ideias de prazer e,

${ }^{17}$ Cf. Burkert, W. Greek religion. Translated by John Raffan. Basil Blackwell, 1985, p. 125: Zeus is the only name of a Greek god which is entirely transparent etymologically, and which indeed has long been paraded as a model case in Indo-European philology. The same name appears in the Indic sky god "Dyaus pitar", in the Roman "Diespiter/ Juppiter", in the Germanic Tues-day, and the root is found in the Latin "deus", god, "dies", day, and in the Greek "eudia”, fair weather. (...) Only for Greeks and Romans is the Sky Father the highest god, and he is so primarily as a rain and storm god: Zeus is much more a weather god than the etymology would suggest, and this connects him with the weather gods of Asia Minor with whom he was indeed later equated. Already in Mycenaean times Zeus was one of the most important gods, perhaps even the highest god: a month is named after him.

${ }^{18}$ Cf. Robert, J.-N. La vie à la campagne dans l'antiquité romaine. Paris: Les Belles Lettres, 1985, p. 295-296.

${ }^{19}$ Cf. Commelin, P. Nova mitologia grega e romana. Belo Horizonte: Itatiaia, 1983, p. 43-51.

${ }^{20}$ Cf. Ogilvie, R. M. The Romans and their gods. London: Hogarth, 1986, p. 70: Although this calendar satisfactorily settled the absolute dates of all the festivals, it suffered for centuries from failure to reconcile a lunar year of 354 days with a solar year of 365 1/4 days, with the result that incompetent mathematics or political wangling often led to the winter festivals being celebrated in mid-summer.

${ }^{21}$ Cf. Robert, op. cit., p. 298.

22 Cf. Altheim, F. A history of Roman religion. Translated from the German by Harold Mattingly. London: Methuen \& Co., 1938, p. 107.

${ }^{23}$ Cf. Robert, op. cit., p. 295-296.

${ }^{24}$ Cf. Robert, op. cit., p. 301-303. 
mesmo, de uma alegre licenciosidade. ${ }^{25}$ Minerva, a correspondente romana da grega Atena, é por duas vezes evocada por Varrão, neste livro inicial do De re rustica, em razão de sua mítica conexão com a descoberta da oliveira entre os helenos, ${ }^{26}$ enquanto Vênus, na origem uma antiga deusa itálica dos vergéis, ${ }^{27}$ encontra-se bem menos deslocada nesse contexto do que poderia parecer à primeira vista. ${ }^{28}$ Curiosamente, a informação dada por Varrão na passagem citada a respeito de ser Vênus celebrada nas Vinalia de dezenove de agosto não encontra unânime confirmação entre os estudiosos da vida rústica em Roma, pois que alguns, como Jean-Noël Robert, ${ }^{29}$ identificam esta data com um pedido de proteção a Júpiter a fim de que poupe das chuvas outonais os cachos de uva já no ponto de serem colhidos. Linfa e Bom Evento, ${ }^{30}$ por fim, deuses menores, evocam o essencial elemento líquido e uma espécie de nume informe da fortuna, pois, sem o favorecimento da sorte, de nada valeriam os esforços dos agricultores...

Em seguida, a própria ambientação deste primeiro livro do De re rustica se insere em contexto eminentemente sacralizado: num dia de feriado em Roma (a saber, numa data de Feriae Sementiuae) vários interlocutores se reúnem no templo da deusa Tellus, convidados por seu "sacristão", a fim de passarem agradavelmente e com proveito suas horas de tempo livre. Entre eles, encontra-se "Varrão", o representante fictício do autor, Gneu Tremélio Escrofa, um autêntico "agrônomo" de Roma antiga, ${ }^{31} \mathrm{e}$

${ }^{25}$ Cf. Salles, C. Nos submundos da Antiguidade. Tradução de Carlos Nelson Coutinho. São Paulo: Brasiliense, 1983, p. 197: Com efeito, são as prostitutas de Roma que constituem a principal atração das "Floralia": elas desfilam diante dos espectadores, representam "mimos" certamente muito sugestivos $e$ ficam nuas a pedido dos espectadores.

${ }^{26} \mathrm{Cf}$. supra quinta página deste artigo.

${ }^{27}$ Cf. Grimal, P. O amor em Roma. Tradução de Hildegard Fernanda Feist. São Paulo: Martins Fontes, 1991, p. 49: Durante muito tempo se admiraram de que Vênus tenha começado como camponesa, uma divindade rústica que personificava o "encanto" da primavera, dos vergéis em flor, e reinava sobre as hortas.

${ }^{28}$ Cf. comentário de Jacques Heurgon a esta passagem do De re rustica I de Varrão (Varron. Économie rurale. Texte établi, traduit et commenté par Jacques Heurgon. Paris: Les Belles Lettres, 2003a. Livre I, p. 95-96): Selon la tradition antique, reaffirmée par G. Wissowa, ibid., p. 289 sq., Vénus était la déesse des jardins, spécialement des potagers. Vénus, par métonymie, signifiait “olera” les légumes (Fest. Paul. p. $51 \mathrm{~L}$ ).

${ }^{29}$ Cf. Robert, op. cit., p. 303-304.

${ }^{30}$ Cf. comentário de Jacques Heurgon a esta passagem do De re rustica I de Varrão (Varrão, op. cit., 2003 a, p. 96): "Bonus Euentus”, "le bon succès”, est ici particulièrement la personnification de la "belle venue" des "fruges", quand elles "viennent bien", quand elles "viennent à terme".

${ }^{31} \mathrm{Cf}$. Martin, R. Recherches sur les agronomes latins et leurs conceptions économiques et sociales. Paris: Les Belles Lettres, 1971, p. 237: Tout port à croire que Cn. Tremelius Scrofa, dont l'oeuvre ne nous est point parvenue, fut l'un des plus grands parmi les Agronomes latins. Varron, qui, nous l'avons vu, ne ménage ni Caton ni les Saserna, fait de lui le plus grand éloge: Scrofa est considéré, nous dit-il, comme "le Romain le plus savant en matière d'agriculture"; c'est à lui que, de l'avis general, "revient la palme en matière d'économie rurale”. 
Fundânio, o sogro daquele intelectual. Desse modo, embora saibamos que essas Feriae pressupusessem, durante a segunda metade do mês de janeiro, oferendas rituais de grãos a Tellus e das vísceras de uma porca a Ceres, bem como o repouso dos camponeses e bois de arado nas terras (coroados esses últimos de guirlandas de flores!), ${ }^{32}$ as personagens citadas e outras limitam-se, aqui, a trocar conhecimentos sobre as artes do cultivo de todos os grandes tipos vegetais antigos (cereais variados, oliveiras, videiras, árvores frutíferas e de cercadura...); ao término desse diálogo, enfim, que se acaba de maneira surpreendente, chega o liberto do "sacristão" do templo (o aeditumus) aos prantos, pois seu patrono, esfaqueado na cidade de Roma quando a caminho de um encontro com o edil responsável pelo edifício, sucumbira aos ferimentos. ${ }^{33}$ Assim, imaginamos, as chances de que o ritos em honra da deusa devessem ser conduzidos por essa "personagem ausente" e mais especializada faz-nos crer, caso ela não tivesse "morrido" ou ficado retida em Roma durante sua visita à cidade, que se criariam condições fictícias para todos "encenarem" a festa como convinha...

Ainda sobre a presença da religião institucionalizada, importa citar em conjunto as passagens identificadas com I, 2, 18-20 e I, 29, 3. Na primeira, então, desenvolvendose aspectos etiológicos do rito a Líber/ Baco e a Minerva/ Atena, a personagem de Fundânio diz a Ágrio as seguintes palavras:

"Ó Ágrio, cuidado para não exagerar a esse respeito, visto que nas leis também se escreve: 'Certo tipo de gado'. Pois certos animais são danosos e letais às culturas, como esses a que te referiste há pouco, as cabras: elas estragam todas as plantas novas ao pastar, especialmente as videiras e oliveiras. Por isso, então, determinou-se por razões diferentes que uma vítima da espécie caprina fosse levada ao altar de uma divindade e não fosse imolada junto ao altar de outra, pois uma pelo mesmo ódio não queria ver e a outra queria ver morrendo. Assim, deu-se que ao pai Líber, descobridor da videira, os bodes fossem imolados, de modo a serem punidos com a pena de morte; contrariamente, que nada da espécie caprina imolassem a Minerva por causa da oliveira, pois dizem que se torna estéril aquela que estragou: a saliva desses animais é venenosa para seu fruto; por essa razão, também em Atenas não são conduzidos para a Acrópole mais do que uma vez por ano para o sacrifício necessário, a fim de que a oliveira, que se diz ter nascido lá em primeiro lugar, não possa ser tocada pelas cabras". ${ }^{34}$

\footnotetext{
${ }^{32}$ Cf. Robert, op. cit., p. 295.

${ }^{33}$ Cf. De re rustica I, 69.

${ }^{34}$ Cf. De re rustica I, 2, 18-20: Cui Fundanius, "Vide”, inquit, “ne, Agri, istuc sit ab hoc, cum in legibus etiam scribatur 'pecus quoddam'. Quaedam enim pecudes culturae sunt inimicae ac ueneno, ut istae, quas dixisti, caprae. Eae enim omnia nouella sata carpendo corrumpunt, non minimum uites atque oleas. Itaque propterea institutum diuersa de causa ut ex caprino genere ad alii dei aram hostia adduceretur,
} 
A outra passagem citada há pouco insere-se, na verdade, num entorno de teor etimológico, conforme um típico expediente varroniano de explanação da realidade agrária ou de outros tipos. ${ }^{35}$ Dessa maneira, explicando os motivos de se designarem tecnicamente os canteiros elevados entre dois sulcos porcae e de, em tempos passados, ter sido chamado o ato sagrado do oferecimento das entranhas das vítimas aos deuses de porricere, Varrão, recorrendo à erudição gramatical de que, sem dúvida, desfrutou, ${ }^{36}$ associa ambos os termos a um verbo indicador do "produzir" no latim de sua época. Aparentemente, no caso do infinitivo antes designador do gesto sacrificial visto, o autor deseja realçar os vínculos, no tocante às crenças difundidas entre os antigos agricultores romanos, entre a ciosa condução dos ritos devidos e a decorrente fertilidade das terras. ${ }^{37}$

A última passagem do livro primeiro do De re rustica que trazemos à discussão com fins de exemplificar as modalidades teológicas varronianas na obra de nosso interesse foi interpretada por Lucienne Deschamps com conotações aproximadas do afloramento da criticidade filosófica do sábio, em confronto com elementos da

ad alii non sacrificaretur, cum ab eodem odio alter uidere nollet, alter etiam uidere pereuntem uellet. Sic factum ut Libero patri, repertori uitis, hirci immolarentur, proinde ut capite darent poenas; contra ut Mineruae caprini generis nihil immolarent propter oleam, quod eam quam laeserit fieri dicunt sterilem: eius enim saliuam esse fructuis uenenum: hoc nomine etiam Athenis in arcem non inigi, praeterquam semel ad necessarium sacrificium, ne arbor olea, quae primum dicitur ibi nata, a capra tangi possit" (minha tradução).

${ }^{35}$ No De lingua Latina, por sinal, a obra varroniana dedicada a descrever o latim, trata-se da etimologia nos livros II a VII. Nesse contexto, a prática etimológica, compreendida, à maneira estoica, como instrumento de aproximação de uma realidade em que as palavras de fato se enraizariam (cf. Lyons, J. Introdução à linguística teórica. Tradução de Rosa Virgínia Mattos e Silva e Hélio Pimentel. São Paulo: Cia. Editora Nacional/ Edusp, 1979, p. 4-6), presta-se a esclarecer vocábulos como os da vida rural romana e da religião: V, 10, 71 - Velinia (dea)/ Velinus (lacus), Tiberinus (deus)/ Tiber (flumen)...

${ }^{36}$ Cf. Cardoso, Z. de A. A literatura latina. São Paulo: Martins Fontes, 2003, p. 190: A gramática foi escrita entre 47 e 45 a.C. Dedicada a Cícero, compunha-se de 25 livros. O primeiro servia de prefácio aos demais, nos quais se abordavam a etimologia da língua latina, sua morfologia e sintaxe. Embora as questões linguísticas apresentadas sejam hoje motivo de controvérsia e se façam grandes restrições a algumas das hipóteses sugeridas pelo escritor, "Sobre a língua latina" é um precioso documento, desde que analisado com o devido cuidado. O estudo sobre o vocabulário poético, a descrição morfológica da língua latina e as reflexões sobre analogias são de grande interesse para os estudiosos do assunto.

${ }^{37}$ Esse pensamento, tão difundido na antiga religiosidade romana, é ecoado em Geórgicas I 338-350, a propósito dos ritos em honra de Ceres: In primis uenerare deos atque annua magnael sacra refer Cereri laetis operatus in herbis,/ extremae sub casum hiemis, iam uere sereno./ Tum pingues agni et tum mollissima uina;/ tum somni dulces densaeque in montibus umbrae./ Cuncta tibi Cererem pubes agrestis adoret;/ quoi tu lacte fauos et miti dilue Baccho;/ terque nouas circum felix eat hóstia fruges,/ omnis quam chorus et socii comitentur ouantes/ et Cererem clamore uocent in tecta; neque ante/ falcem maturis quisquam supponat aristis,/ quam Cereri torta redimitus tempora quercu/ det motus incompositos et carmina dicat. - "Antes de mais nada, cultua os deuses e restitui os cultos anuais à grande Ceres tendo sacrificado na relva alegre, no finalzinho do inverno, já na primavera serena. Então, os cordeiros são gordos e os vinhos mais suaves; então, os sonos agradáveis e as sombras densas nos montes. Que todos os jovens do campo cultuem Ceres para ti: dilui para ela favos no leite e no vinho suave. Que uma vítima feliz circunde as plantações novas três vezes, todo o coro e os amigos acompanhem-na dando gritos de alegria e chamem Ceres com um clamor para tua casa; e que ninguém aproxime a foice das espigas maduras antes de, cingido nas têmporas com o carvalho torcido, dançar rusticamente e suplicar a Ceres" (minha tradução). 
espiritualidade popular que se poderiam "desqualificar" como crendices. ${ }^{38}$ Desse modo, em De re rustica I, 2, 26-27, as personagens do diálogo criticam aos risos a ingenuidade de certos tratados agrícolas do passado de Roma, os quais chegavam a incorporar não só “despropositadas" receitas para depilação que recorriam à água do cozimento de rãs, mas, ainda, encantamentos para a cura da gota pelo recurso a fórmulas e gestos mágicos repetidos por um certo número de vezes. Parece-nos, do ponto de vista das já reportadas críticas varronianas à religiosidade imaginativa dos poetas, ${ }^{39}$ que nos vemos neste trecho diante de relações com o numinoso que prescindem da total adesão a tudo, como foi característico dos pensadores de variadas escolas filosóficas antigas (estoicos, epicuristas, pitagóricos...), ao rejeitarem o que lhes pareciam meras visões deturpadoras de deus. Assim, a crença em deuses que nascem de gotas de sangue e adulteram, ${ }^{40}$ ou, mutatis mutandis, em doenças que se possam curar supersticiosamente sempre pressuporia um tipo de entrega pessoal ao extraordinário que, sem em nada favorecer a estabilidade do corpo civil ou o seguro entendimento do sagrado, também não se presta a usos eficazes para a vida prática.

Em De re rustica II, por sua vez, além de abundarem as referências à religiosidade institucionalizada do culto romano, também encontramos alguns mitos a tematizarem, de maneira imaginativa e, como diria Varrão, "poética" a presença do sagrado no mundo. Iniciando, portanto, este panorama do livro segundo da obra pelo último ponto, citamos, a título de exemplificação, a referência a Hércules em II, 1, 6, a Fáustulo, Rômulo e Remo em II, 1, 9, a Netuno e Melanipa em II, 5, 5, e ao mito de Diana e Acteão em II, 9, 9-10. Sobre as duas primeiras referências, introduzidas logo no capítulo inicial do texto, trata-se de parte dos esforços para enobrecer a pecuária, indicando-lhe a antiguidade e a importância desde tempos recuados por terem, de algum modo, lidado com animais longínquos heróis (ou semi-deuses) consagrados pelo imaginário comum. Nesse sentido, Hércules, o semi-deus grego amplamente cultuado em Roma (a lenda o dava por filho tebano de Zeus e Alcmena) como símbolo da força e do renascimento na imortalidade, é lembrado nesta específica passagem de Varrão sob a forma de quem, em uma de suas aventuras, roubara caprinos e ovinos ao aventurar-se nos Jardins das Hespérides (as filhas de Atlas) para tomar-lhes os pomos de ouro. ${ }^{41}$

\footnotetext{
${ }^{38}$ Cf. Deschamps, op. cit., p. 293.

${ }^{39} \mathrm{Cf}$. supra nota 2.

${ }^{40} \mathrm{Cf}$. nota anterior.

${ }^{41}$ Cf. Commelin, op. cit., p. 184 (trata-se, na verdade, do décimo primeiro dos famosos "Doze trabalhos" dessa personagem mítica. Os demais, na ordem discriminada por Commelin, são a- o combate ao Leão de
} 
Fáustulo, Rômulo e Remo, por sua vez, que Varrão cita no mesmo entorno textual, correspondem às conhecidas figuras do imaginário latino que estariam na raiz da própria fundação lendária de Roma. Como se conta, assim, os jovens eram filhos de Marte e da Vestal Reia Sílvia, a quem seu tio, o rei Amúlio de Alba-Longa, lançara ao Tibre num cesto a fim de afogá-los e evitar a futura concorrência pelo trono de sua cidade. Por intervenção divina, porém, os meninos chegaram flutuando a uma parte das margens onde os achou e amamentou uma loba, salvando-os da morte pela fome. Em seguida, encontrados pelo humilde pastor de nome Fáustulo, foram recolhidos à sua cabana e criados nessa profissão por tal personagem e por sua esposa, vivendo em grande simplicidade até a fundação de Roma por Rômulo, com um grupo de moços salteadores das montanhas, e a morte de Remo em suas mãos por desafio à soberania fraterna no interior da cidade recém-fundada. ${ }^{42}$ Em Roma, uma gruta do monte Palatino, chamada Luperco em homenagem a um Fauno protetor do lugar (Faunus Lupercus), assinalava um suposto sítio onde os gêmeos teriam sido miraculosamente amamentados pela loba. A cada dia quinze de fevereiro, por sinal, ocorriam em Roma as chamadas "Lupercais", festas de culto à fertilidade em que se assistia a ritos inusitados: alguns jovens de famílias patrícias sacrificavam no local dois bodes e um cão; tendo-se, em seguida, ungido com o sangue do sacrifício, saíam correndo nus pelas ruas da cidade, apenas mal cobertos com tiras de couro recortadas dos bodes e do cão mortos e "chicoteando" alegres os passantes com elas. ${ }^{43}$ Ser casualmente atingido por esses golpes de pele recém-esfolada era considerado sinal de bom-agouro e portador de fertilidade, sobretudo para as esposas em idade reprodutiva.

As duas referências míticas seguintes, embora também "dignificadoras" dos humildes fazeres dos pastores e pecuaristas por mostrarem os animais em conexão ou serviço aos deuses, revestem-se de peculiaridades em relação às já vistas. Em primeiro lugar, aparentemente o mito comum de Netuno e dessa sua esposa, Melanipa, opaco para os estudiosos modernos, ${ }^{44}$ não deve ter sido tão difundido em Roma quanto as

Nemeia, b- o combate contra a Hidra de Lerna, c- o combate contra o javali de Erimanto, d- a vitória contra a corça de pés de bronze, e- o extermínio dos pássaros do lago Estínfalo, f- ter domado o touro de Creta, g- o furto dos cavalos de Diomedes, h- a vitória contra as Amazonas, i- a limpeza das estrebarias de Aúgias, k- o combate contra Gérion e o roubo de seus bois e 1- a retirada de Teseu dos Infernos).

${ }^{42}$ Cf. Commelin, op. cit., p. 286-288.

${ }^{43}$ Cf. Ogilvie, op. cit., p. 77-78.

${ }^{44}$ Cf. comentário de Charles Guiraud a esta passagem do De re rustica II de Varrão (Varron. Économie rurale. Texte établi, traduit et commenté par Charles Guiraud. Paris: Les Belles Lettres, 2003 b. Livre II, p. 131-132): La faute par intervension est fréquente dans les manuscrits car il s'agit, bien entendu, de Mélanippe, cf. notre correction. Il y a eu plusieurs Mélanippe. En ce qui concerne celle don't parle ici 
histórias de Hércules e da criação de Rômulo e Remo por Fáustulo. Ainda assim, essa lenda serve para "dourar" o tema material da criação do gado bovino pela menção de que os filhos do casal teriam sido salvos do esmagamento num estábulo ao se porem seguros sobre o dorso de bois.

Por outro lado, a menção ao mito de Acteão e Diana caçadora, que se insere no capítulo de De re rustica II ocupado de descrever a criação de equinos, apresenta-nos os animais ou a vida pastoril não em sua face construtiva, de acrescentar meios de sobrevivência aos recursos humanos, mas, sim, sob um viés funesto caso negligenciados. ${ }^{45}$ A respeito do terrível destino de Acteão, basta lembrarmo-nos de que esse príncipe tebano, primo do famigerado Penteu, fora cruelmente metamorfoseado em cervo e devorado pelos próprios cães de caça ao ter surpreendido por acaso a deusa Diana nua, enquanto ela se banhava nos bosques com as ninfas. ${ }^{46}$ Nesse caso, por conseguinte, cães mal alimentados, numa imagem algo hiperbólica, poderiam chegar a ser como os do mito admonitório em jogo, pois que, talvez, atacariam com dentadas os próprios donos em razão de sua fome e frustração dessa necessidade básica.

Sob o aspecto do culto religioso, naturalmente muito difundido neste livro específico dos diálogos agrários varronianos por serem, na maioria das vezes, como se pode imaginar, os animais mortos ou seus fluidos e partes corporais (carne, vísceras, sangue, gordura, leite...) os itens preferidos nos sacrifícios, ${ }^{47}$ podemos citar vários exemplos de tematização no presente segmento da obra. De início, em se tratando o autor do De re rustica de um polígrafo, ${ }^{48}$ que se dedicara, antes, inclusive a compor uma obra (perdida) intitulada Quaestiones Plautinae, temos duas referências de teor

Varron, elle eut de Poseidon-Neptune deux fils, Boeotos et Éole II. Le thème de Mélanippe avait été traité dans deux tragédies perdues d'Euripide, "Mélanippé enchainée" et "Mélanippé la philosophe". C'était également le titre d'une tragédie d'Accius (Cic. "Off." 1, 114; Varron, "de ling. Lat. 7, 65) et d'Énnius (Gell. 5, 11, 12). Varron semble être le seul à parler d'un boeuf qui aurait empêché les enfants de Mélanippe d'être écrasés par un troupeau.

${ }^{45}$ Cf. De re rustica II, 9, 9: Cibatus canis propior hominis quam ouis. Pascitur enim eduliis et ossibus, non herbis aut fronde. Diligenter ut habeat cibaria prouidendum. Fames enim hos ad quaerendum cibum ducet, si non praebebitur, et a pecore abducet; nisi si, ut quidam putant, etiam illuc peruenerint, prouerbium ut tollant anticum uel etiam ut mython aperiant de Actaeone atque in dominum adferant dentes. - "A alimentação do cão é mais próxima do homem que da ovelha. Alimentam-se, com efeito, de comida e ossos, não de ervas ou folhas. Deve-se cuidar com empenho de que tenha víveres. A fome, com efeito, vai levá-los a buscar alimento se não for oferecido, e afastará do rebanho; se não é que, como alguns entendem, chegarão a descumprir o velho provérbio ou mesmo a encenar o mito de Acteão e a usarem os dentes contra o senhor" (minha tradução).

${ }^{46}$ Cf. Commelin, op. cit., p. 48.

${ }^{47}$ Cf. Burkert, op. cit., p. 59-64.

${ }^{48}$ Cf. sobre vida e poligrafia de Varrão, além do supracitado Boissier, sucinto Miguel, L. A. Varrón. Madrid: Clásicas, 2000. 
religioso à comédia romana neste livro: na primeira, de II, 1, 20, explica-se terem sido chamado sacres ("sagrados") por Plauto os porcos em estado de pureza para os sacrifícios; a menção seguinte ao nome desse célebre dramaturgo ocorre em II, 4, 16, também a propósito da designação de sacres ("sagrados”) para os suínos votados e prontos para os sacrifícios. Dessa vez, porém, é observado que essa designação ocorrera, especificamente, na peça Menaecmi, num contexto em que, desejando purificar um homem ensandecido, uma das personagens perguntara aos habitantes de Epidamno: "Quanto custam aqui os porcos sacres?".

Durante a própria ocasião de encontro dos amigos para interagirem, em troca recíproca de conhecimentos, sobre a arte pecuária no livro II do De re rustica, entrevemos, ainda, que de fato se realizam ou vão realizar atos religiosos. Assim, em II, 5, 1-2, o retardatário Lucieno fala nos termos seguintes aos que já se encontravam reunidos em interação há algum tempo:

Eis o que disse. Mas o senador Quinto Lucieno, homem muito gentil, brincalhão e amigo de todos nós, disse ao entrar: "Salve, concidadãos do Epiro. De manhã cumprimentei meu Varrão, pastor do povo". Tendo um cumprimentado e outro brincado por ter vindo tão tarde ao compromisso, ele disse: "Eu já vou vê-los, patifes, e para cá vou trazer minha pele e chicote. Mas tu, Múrrio, vem assistir-me enquanto pago os Lares, para poderes testemunhar se depois reclamarem de mim". Ático disse a Múrrio: "Conta-lhe as discussões que tivemos e o que falta, para que venha preparado a seu papel. Nós, enquanto isso, teçamos o segundo ato, sobre os animais maiores". ${ }^{4}$

Os deuses Lares, que ele menciona, aqui, quando convida Múrrio para acompanhá-lo ao sacrifício, são um dos mais santos pilares da religião de Roma. ${ }^{50}$ Correspondendo aos ancestrais mortos e divinizados de cada família, eram cultuados pelo pater familias diante do altar doméstico (lararium) com ofertas de vinho, grãos de sal e incenso. Uma festa de origens rústicas, por sinal, comemorava esses entes espirituais entre os latinos: referimo-nos às Compitaliae, passadas em algum dia móvel do início do mês de janeiro. Nesse tempo, de início, o compitum, ponto sagrado de

\footnotetext{
${ }^{49}$ Cf. De re rustica II, 5, 1-2: At Quintus Lucienus senator, homo quamuis humanus ac iocosus, introiens, familiaris omnium nostrum, Synepirotae, inquit, chairete; Scrofam enim et Varronem nostrum, poimena laon, mane salutaui. Cum alius eum salutasset, alius conuiciatus esset, qui tam sero uenisset ad constitutum, Videbo iam uos, inquit, balatrones, et hoc adferam meum corium et flagra. Tu uero, Murri, ueni mi aduocatus, dum asses soluo Laribus, si postea a me repetant, ut testimonium perhibere possis. Atticus Murrio, Narra isti, inquit, eadem, qui sermones sint habiti et quid reliqui sit, ut ad partes paratus ueniat; nos interea secundum actum de maioribus adtexamus (minha tradução).

${ }^{50}$ Cf. Commelin, op. cit., p. 150-151.
} 
convergência dos limites entre quatro propriedades rurais, era palco de oferendas, enquanto os senhores das terras, tendo pendurado em casa um boneco de lã para cada homem livre e uma bola dessa mesma matéria para cada escravo, descansavam, simbolicamente suspendendo o arado no altar. ${ }^{51}$ Por essa devoção acreditavam, nos campos e, depois, nas cidades, garantir o resguardo contra os males para os moradores das casas (até os escravos da família) e as terras adjacentes a elas.

A outra passagem de rito religioso coevo a esta hora de "conversa de gado" se dá quando "chega" o liberto de Menates, uma das personagens deste segundo diálogo agrícola, e avisa da conclusão do preparo dos bolos sagrados e demais itens necessários ao sacrifício (II, 8, 1). Embora provavelmente se trate do próprio rito que, talvez, justificaria num dia santo a reunião desses "pecuaristas", observa-se no contexto que a personagem de "Varrão" não permite a dispersão dos amigos antes de se terem, de fato, tratado de todos os pontos da criação animal pré-definidos no início do diálogo: ${ }^{52}$ ao fim dessa segunda parte da obra, porém, alguns dos interlocutores dirigem-se ao tal sacrifício, alguns para suas casas e alguns para os jardins de um Vítulo.

As referências restantes ao âmbito da religiosidade em De re rustica II parecemnos, basicamente, corresponder às seguintes: no mesmo capítulo inicial dessa parte do tríptico, quando "Varrão" fala de aspectos históricos e culturais das artes de criação do gado a fim de enaltecer a prática dos pecuaristas, citam-se as anuais "Parílias" de vinte e um de abril e a prática purificadora da Suouetaurilia. No primeiro evento, encontramonos diante de uma das mais tradicionais festas do calendário religioso latino, inclusive por se dar no dia mesmo de suposta fundação da cidade: em tal data, dedicada à deusa pastoril Pales, eram-lhe feitas oferendas das cinzas de um feto de vaca retirado do ventre de sua mãe sacrificada, de sangue de cavalo e de hastes de favas, pois se tratava de uma entidade protetora de rebanhos, que se alimentam com palha. ${ }^{53}$ Ao que tudo indica, a razão de ter sido essa festividade celebrada no mesmo dia tradicional da fundação de Roma se relaciona de algum modo ao "fato", como vimos, de que Rômulo, o fundador, e Remo, seu irmão, tivessem sido pastores. O segundo rito mencionado, as Suouetauriliae, correspondia a uma prática purificadora típica dos campos latinos, em que eram cerimonialmente conduzidos ao redor dos limites um porco (sus), uma ovelha

\footnotetext{
${ }^{51}$ Cf. Ogilvie, op. cit., p. 74.

${ }^{52}$ Cf. De re rustica II, 8, 1: Ego uero, inquam, vos ante ire non patiar, antequam mihi reddideritis tertium actum de mulis, de canibus, de pastoribus. - "Na verdade", digo, "eu não deixarei que partais antes de me representardes o terceiro ato, sobre os mulos, os cães e os pastores" (minha tradução).

${ }^{53}$ Cf. Ogilvie, op. cit., p. 81-82.
} 
(ouis) e um touro (taurus) ${ }^{54}$ tratava-se de um rito, segundo nos mostra o De agri cultura CXLI de Catão Censor, dedicado a Marte.

Poder-se-iam, por fim, citar em De re rustica II como trechos de "afloramento" do sagrado ainda a menção a serem chamados de opimi ("gordos”, II, 1, 20) os bois que se destinam ao sacrifício nos templos dos grandes deuses pátrios; as tantas referências seguidas a alguns usos sacrificiais dos porcos entre os latinos e os etruscos (II, 4, 9-10), julgando o autor terem esses sido a primeira espécie animal a sofrer imolações; a lembrança do rito romano das Hordicidiae, pois, na data do quinze de abril, uma vaca horda ("prenhe", II, 5, 6-7) era imolada;" a comparação entre os bois de escol a abundarem no Epiro e a faltarem na Itália (onde, todavia, os melhores são reservados para o sacrifício divino - II, 5, 10) e o curioso tema da deusa dita Rumina em latim, que se cria guardiã da figueira Ruminalis - sob cuja copa, segundo certas tradições, Rômulo e Remo teriam sido amamentados pela loba lendária -, e era cultuada pelos pastores com oferendas de leite (nunca de sangue - II, 11, 5) em sua pequenina capela...

Se, como bem observou Deschamps, de fato não notamos no culto, esclarecido e filosófico Varrão o mesmo "frenesi” do sagrado visto em Catão Censor, ${ }^{56}$ que o precede na tradição dos escritos agrários latinos com seu conhecido De agri cultura, também não seria o caso de propor um autor do De re rustica taxativamente "cético" por sabermos que ele não cria na divindade de Rômulo ou nas histórias de seu nascimento pela misteriosa fecundação de uma virgem Vestal por Marte, criticou irônico a crédula recorrência à magia no livro primeiro de sua obra agrária ${ }^{57}$ e manifestou, nas Antiquitates diuinae, anuências "utilitárias" à religião civil, segundo praticada pelos Pontífices e, em geral, seguida pelo povo. Afinal, em seu ecletismo filosófico, em que cabia mesmo o viés estoico, ${ }^{58}$ não seria impossível, dadas as práticas de leitura alegórica do mundo e da religiosidade amiúde conduzidas pelos adeptos dessa Escola, ${ }^{59}$ que

\footnotetext{
${ }^{54} \mathrm{Cf}$. Ferguson, J. The religions of the Roman empire. London: Thames and Hudson, 1982, p. 114.

${ }^{55}$ Cf. Ogilvie, op. cit., p. 82.

${ }^{56}$ Cf. Deschamps, op. cit., p. 289.

${ }^{57} \mathrm{Cf}$. De re rustica I, 2, 26-27.

${ }^{58}$ Cf. Lehmann, Y. Polythéisme et monothéisme chez Varron. Latomus. Bruxelles, vol. CCXXXVII, p. 228, 1997: Varron ne pouvait manquer d'exprimer cette ambiguité théologique en termes de religion officielle: dès lors c'est Jupiter - réplique du Dieu cosmique dans le culte romain - qui designe aussi bien l'univers en général que l'éther en particulier.

${ }^{59}$ Cf. Ferguson, op. cit., p. 193: The Stoics were pantheists. Jupiter, said Cato in the pages of Lucan, is everything you see and every movement you make; the totality of all things seen and unseen, said Seneca. He is called by many names: God, Zeus or Jupiter, Nature, the Universe, Omnipotence, Fire, Spirit or Breath, Aether, Logos (the Divine Reason or Word).
} 
divisasse uma mínima centelha do sagrado mesmo nos ritos convencionais do povo de Roma.

Por outro lado, a abundância e a extensão do tratamento de temas mítico-divinos ou, propriamente, religiosos nas páginas das duas partes iniciais do De re rustica atestam, sem sombra de dúvida, o detido valor que Varrão reatino concedeu às distintas conformações do sagrado quando abordou o assunto da cultura camponesa itálica.

\section{Referências}

ALTHEIM, F. A history of Roman religion. Translated from the German by Harold Mattingly. London: Methuen \& Co., 1938.

AUGUSTO; SUETÔNIO. A vida e os feitos do divino Augusto. Tradução de Matheus Trevizam, Paulo Sérgio de Vasconcellos e Antônio Martinez de Rezende. Belo Horizonte: UFMG, 2007.

BOISSIER, P. Étude sur la vie et les ouvrages de M. T. Varron. Paris: Hachette, 1861.

BURKERT, W. Greek religion. Translated by John Raffan. Basil Blackwell, 1985.

CARDOSO, Z. de A. A literatura latina. São Paulo: Martins Fontes, 2003.

CATO; VARRO. On agriculture. With an English translation by W. D. Hooper, revised by H. B. Ash. Cambridge, Mass./ London: Harvard University Press, 2006.

COMMELIN, P. Nova mitologia grega e romana. Belo Horizonte: Itatiaia, 1983.

DELLA CORTE, F. Passato e presente in Varrone. In: Opuscula VI. Genova: Istituto di Filologia Classica e Medievale, 1978, p. 213-230.

Varrone. Il terzo gran lume romano. Genova: Istituto Universitario di Magistero, 1954.

DESCHAMPS, L. Varron et le sacré. Bulletin de l'association Guillaume Budé. Paris, p. 289-296, juin 1990.

Enciclopedia Virgiliana. Roma: Istituto della Enciclopedia italiana, 1990. Vol. V. 
FERGUSON, J. The religions of the Roman empire. London: Thames and Hudson, 1982.

GRIMAL, P. La littérature latine. Paris: Fayard, 1994.

O amor em Roma. Tradução de Hildegard Fernanda Feist. São Paulo: Martins Fontes, 1991.

LEHMANN, Y. Polythéisme et monothéisme chez Varron. Latomus. Bruxelles, vol. CCXXXVII, p. 226-242, 1997.

LYONS, J. Introdução à linguística teórica. Tradução de Rosa Virgínia Mattos e Silva e Hélio Pimentel. São Paulo: Cia. Editora Nacional/ Edusp, 1979.

MARTIN, R. Recherches sur les agronomes latins et leurs conceptions économiques et sociales. Paris: Les Belles Lettres, 1971.

MIGUEL, L. A. Varrón. Madrid: Clásicas, 2000.

PEREIRA, M. H. R. Estudos de história da cultura clássica. II volume: cultura romana. Lisboa: Gulbenkian, 1990.

ROBERT, J.-N. La vie à la campagne dans l'antiquité romaine. Paris: Les Belles Lettres, 1985.

SALLES, C. Nos submundos da Antiguidade. Tradução de Carlos Nelson Coutinho. São Paulo: Brasiliense, 1983.

SAN AGUSTín. Obras completas de San Agustín. La ciudad de Dios. Traducción de Santos Santamarta del Río y Miguel Fuertes Lanero. Madrid: Biblioteca de autores cristianos, 1988. Libro I.

VARRON. Économie rurale. Texte établi, traduit et commenté par Jacques Heurgon. Paris: Les Belles Lettres, 2003a. Livre I.

. Économie rurale. Texte établi, traduit et commenté par Charles Guiraud. Paris: Les Belles Lettres, 2003 b. Livre II.

VIRGILE. Géorgiques. Texte traduit par E. de Saint-Denis. Introduction, notes et postface de J. Pigeaud. Paris: Les Belles Lettres, 1998. 